\title{
Osteoporosis in adult with Marfan syndrome: casuality or causality?
}

\section{Osteoporosi in paziente con sindrome di Marfan: casualità o causalità?}

\author{
M. D'Amore, G. Minenna, P. Scagliusi, S. D'Amore ${ }^{1}$ \\ DIMIMP - Reumatology, University of Bari, Italy; \\ ${ }^{I}$ DIMIMP - Emergency Medicine, University of Bari, Italy
}

\begin{abstract}
RIASSUNTO
La sindrome di Marfan (MFS) è una malattia del tessuto connettivo trasmesso con carattere autosomico dominante. Recenti studi hanno evidenziato riduzione della BMD al rachide lombare, al collo del femore e gran trocantere di adulti e bambini affetti da MFS. Molta è l'incertezza circa la causa della riduzione della BMD: gli Autori presentano il caso di una paziente affetta da MFS con alterazione dei markers del turnover osseo.
\end{abstract}

Reumatismo, 2005; 57(2):125-127

\section{INTRODUCTION}

$\mathrm{N}$ early 100 years ago, Antoine Marfan first described a recurrent systemic disorder of connective tissue characterized by overgrowth of the long bones (1). It took an additional 50 years before ocular and cardiovascular manifestations were associated with this disorder, now termed Marfan syndrome (MFS). MFS is an inherited connective tissue disorder transmitted as an autosomal dominant trait. This relatively common genetic condition affects approximately 2 to 3 per 10,000 individuals, without a particular gender, racial, geographic, or ethnic predilection (2). The disorder results from mutations in the fibrillin-1 (FBN1) gene located on chromosome 15q21.1(3). Approximately $15 \%$ of cases occur in the absence of a family history, representing new mutations; infact to date, over 550 mutations have been identified in patients with MFS and related connective tissue diseases. However, about a half of MFS cases do not possess mutations in the FBN1 gene. These findings raise the possibility that variants located in

Indirizzo per la corrispondenza:

Prof. Massimo D'Amore

Viale Salandra, 43

70124 Bari

E-mail: m.damore@cimedoc.uniba.it other genes cause or modify MFS. Three novel FBN1mutations and ten FBN3 single nucleotide polymorphisms (SNPs) are identified (4). The gene encodes the glycoprotein fibrillin, a major building block of microfibrils, which constitute the structural components of the suspensory ligament of the lens and serve as substrate for elastin in the aorta and other connective tissues. Abnormalities involving microfibrils weaken the aortic wall. Progressive aortic dilatation and eventual aortic dissection occur because of tension caused by left ventricular ejection impulses. Likewise, deficient fibrillin deposition leads to reduced structural integrity of the lens zonules, ligaments, lung airways and spinal dura. Production of abnormal fibrillin1 monomers from the mutated gene disrupts the multimerization of fibrillin-1 and prevents microfibril formation. Abnormalities of the connective tissue protein, fibrillin, cause a variety of distinct problems in the affected individual, of which the musculoskeletal, cardiac, and ocular system impaired structural integrity predominate. Cardinal features of the disorder include tall stature, arachnodactily (abnormally long and thin digits), ectopia lens, mitral valve prolapse, aortic root dilatation and dissection. The main cause of morbidity is represented by the thoracic aortic dissection/ aneurysm that is responsible for $80 \%$ of the deaths, interatrial septal defect and aortic bicuspid 
valve had the same prevalence than in subjects without Marfan syndrome (5).

The major clinical findings of Marfan syndrome involve three major organ systems, including the ocular, skeletal and cardiovascular systems. Skeletal findings include increased height and arm span, anterior chest deformity (pectus excavatum or carinatum), mild to moderate joint laxity, vertebral column deformity (scoliosis and thoracic lordosis), a narrow, highly arched palate and a narrow jaw, resulting in crowded dentition, pes planus, joint hypermobility and arachnodactyly (6). Identification and proper management of the disorder can improve the prognosis greatly, however, and extend the patient's life spain (2). Early diagnosis is essential for a positive course of management. Marfan's syndrome can have fatal consequences and is often underdiagnosed and misdiagnosed. Its diagnosis is sometimes difficult and should always be evoked in the face of a non-atheromatous aneurysm of the ascending aorta, lead to family screening in the search for aneurysms in any relatives, and an ophthalmological and rheumatological examination in the search for extracardiac signs. The diagnosis made suggests the dilatation of the aorta can be limited by proscribing violent sports and prescribing beta-blockers. The diameter of the ascending aorta should be measured with an annual ultrasound in order to propose a surgical replacement of the ascending aorta, before a complication (above all aortic dissection) arises. Besides, fibrillin has been identified in bone and may be involved in binding calcium. It is possible that abnormal fibrillin could play a role in altering the distribution of mechanically induced strain or in affecting bone mineralization (7). Bone mineral density (BMD) studies in children with MFS, have demonstrated reductions at the femoral neck and in women with MFS, BMD was reduced in the lumbar spine and at the total hip (7). Other study has reported the decrease in BMD similar in men and women at both the hip and the radius; BMD in MFS patients is significantly decreased at cortical compared with trabecular sites (8). MFS has significant impact on daily life activities, but the majority of patients come to terms with their condition. Acceptance is mainly determined by subjective severity, and less by physical symptoms as reported by the patients themselves. It is important to stimulate a positive attitude towards MFS (9).

We report a case of a female patient of 44 years old. The above mentioned patient has had regular lifestyle and physical activity too until she was 18 years old, when she experienced an operation for bilateral subluxation of crystalline. In that occasion she presented mitral prolapse disease. Anamnesis was still hidden until she was 43 years old when she was affected by severe rachialgia, not explained by scoliosis. It could assume a Marfan syndrome the patient submitted to a molecular analysis of FBN1 gene, showed heterozygous for a missens mutation in exon 4, Cys123Tyr, confirming Marfan syndrome disease. For this reason, the patient decided to do several laboratory and instrumental analysis to define pathogenesis of her disease. These exams, done in a period between 12 months (2003/2004), were normal: hemochrome, glycemia, transaminase, gamma glutamyl transferase, alcaline phosphatase, total bilirubin (TB), direct bilirubin (DB), indirect bilirubin (IB), creatinemia, azotemia, creatine kinase (CPK), lactic acid dehydrogenase (LDH), total cholesterol, HDL cholesterol, triglyceride, uricemia, dosage of hormone (patient presented a normal menstrual cycle): free triiodothyronine, free tetraiodothyronine, thyroid-stimulating hormone (TSH), anti-thyroperoxidase, anti-thyroglobulin, parathormone (PTH), estradiol, follicle-stimulating hormone (FSH), luteotropin, prolactin (PRL), progesterone, testosterone, plasma cortisol levels, urinary cortisol, adrenocorticotropic hormone (ACTH). The patient was submitted at echocardiography that confirmed a mitral prolapse and X-ray of the dorsal and lombar spine which showed scoliosis and a severe decrease of bone mass. It was planned then, densitometer exam and bone turnover markers monitoring. Dual energy X-ray absorptiometry analysis (DXA), which was performed on femoral neck and lombar spine (L2-L4), demonstrated significantly reduced femoral neck BMD $0.631 \mathrm{~g} / \mathrm{cm}^{2}$ (T-score -2.5) and lombar spine BMD $0.753 \mathrm{~g} / \mathrm{cm}^{2}$ (T-score -2.7). Analysis of phosphocalcic metabolism showed a small increase of osteocalcine: $41 \mathrm{ng} / \mathrm{ml}$ $(5,0-25,0)$ and of alcaline phosphatase bone isoenzyme: 47U/L (12-26) and a significant increase of urinary N-telopeptide: $153 \mathrm{BCE} / \mathrm{mMcreat}$. (14,0$87,0)$. This provides evidence of a clinical picture of "Osteoporosis in a patient with Marfan syndrome".

In order to deeply valuate our knowledge, we describe a case report that confirms previous reports of an association between decreased bone mineral density (BMD), which occurs in the spine, femoral necks and greater trochanters, and some adults and children (9) with Marfan syndrome (10). N. Carter et al. (11) have assumed, referring to the studies 
made before, that BMD decrease in men and women with MSF may be due to mutations of the fibrillin gene or to environmental issues such as reduced exercise leading to sub- optimal peak bone mass (even if we could not associate this case to our patient). We'd like to focus particular attention on the existence of a real osteoporosis case in Marfan patients, visible through the growth of bone markers and from X-Ray analysis. Further investiga- tions will be done in future in order to deeply investigate the natural history of BMD in adults affected by Marfan with a careful monitoring of the traditional parameters, always significant, of bone turnover. According to tradition, may we assume that abnormal fibrillin or reduced exercise could influence BMD or could we explore new and unknown mechanisms responsible of osteoporosis appearance?

\section{SUMMARY}

Marfan syndrome (MFS) is an inherited connective tissue disorder transmitted as an autosomal dominant trait. Recent studies indicate that decreased bone mineral density (BMD) occurs in the spine, femoral necks and greater trochanters of some adults and children with MFS. Since there is uncertainty regarding the BMD status of patients with MFS, the AA. present a case report on a female patient with MFS and alteration of phosphocalcic metabolism.

Key words - Marfan syndrome, osteopenia, bone mineral density.

Parole chiave - Sindrome di Marfan, osteopenia, densità minerale ossea

\section{REFERENCES}

1. Marfan AB. Un cas de deformation congenitale des quatre membres plus prononcé aux extrémités charactériseée par l'allongement des os avec un certain degré d'amincissement. Bull Mém Soc Méd Hop Paris 1896; 13:220-26.

2. Grimes SJ, Acheson LS, Matthews AL, Wiesner GL. Clinical consult: Marfan syndrome. Prim Care 2004; 31:739-42,xii.

3. Kainulainen K, Pulkkinen L, Savolainen A, Kaitila I, Peltonen L. Location on chromosome 15 of the gene defect causing Marfan syndrome. New Engl J Med 1990; 323:935-93.

4. Uyeda T, Takahashi T, Eto S, Sato T, Xu G, Kanezaki $\mathrm{R}$, et al. Three novel mutations of the fibrillin-1 gene and ten single nucleotide polymorphisms of the fibrillin-3 gene in Marfan syndrome patients. J Hum Genet 2004; 49:404-7.

5. Porciani MC, Attanasio M, Lepri V, Lapini I, Demarchi G, Padeletti L, et al. Prevalence of cardiovascular manifestations in Marfan syndrome. Ital Heart J Suppl 2004; 5:647-52.

6. De Paepe A, Devereux RB, Dietz HC, Hennekam RC, Pyeritz RE. Revised diagnostic criteria for the Marfan syndrome. Am J Med Genet 1996 24;62:417-26.

7. Kohlmeier L, Gasner C, Bachrach L, Marcus R. The bone mineral status of patients with Marfan syndrome. J Bone Miner Res 1995; 10:1550-5.

8. Le Parc JM, Plantin P, Jondeau G, Goldschild M, Albert $\mathrm{M}$, Boileau C. Bone mineral density in sixty adult patients with Marfan syndrome. Osteoporos Int 1999; 10:475-9.

9. Giampietro PF, Peterson M, Schneider R, Davis JG, Raggio $\mathrm{C}$, Myers $\mathrm{E}$, et al. Assessment of bone mineral density in adults and children with Marfan syndrome. Osteoporos Int 2003; 14:559-63.

10. De Bie S, De Paepe A, Delvaux I, Davies S, Hennekam RC. Marfan syndrome in Europe. Community Genet 2004; 7:216-25.

11. Carter N, Duncan E, Wordsworth P. Bone mineral density in adults with Marfan syndrome. Reumatology 2000; 39:307-9. 